\title{
TRADUCIR A GÜNTER GRASS
}

\author{
Manuel Maldonado Alemán \\ Universidad de Sevilla
}

\begin{abstract}
Following a theoretical introduction to the specificity of the translation process, the difficulties in translating Günter Grass' narrative work into Spanish are analyzed concentrating on the difficulties in translating Ein weites Feld and Mein Jahrhundert.
\end{abstract}

\section{EL PROCESO DE TRADUCCIÓN}

La importancia que la traducción ejerce en la difusión de la cultura y, en especial, de la literatura es incuestionable. La intervención mediadora de la traducción es fundamental en muchos procesos de transmisión e intercambio cultural y literario (Eco 1994). En el pasado, incluso, su influencia ha sido determinante en el surgimiento y desarrollo de nuevas literaturas (García Yebra 1981: 9). Gracias al reconocimiento explícito de esa importancia, la teoría y la metodología de la traducción han experimentado un singular desarrollo en las últimas décadas. Sus postulados acerca del proceso traslativo han evolucionado desde un acercamiento formalista, centrado en la lengua, hacia los conceptos más amplios de contexto, situación histórica y convenciones literarias o culturales (Albaladejo 1992; Morillas/ Arias 1997; Stolze 1997). Si tradicionalmente el procedimiento del estudio de la traducción consistía en aislar los fenómenos lingüísticos, especialmente las palabras, y tratarlos de una forma inconexa y abstracta, en la actualidad los modelos teóricos, conscientes de la complejidad del fenómeno traslativo, se ocupan de la red de relaciones en las que aparecen insertadas las unidades lingüísticas: el texto, la situación comunicativa y el contexto cultural. También el texto se sitúa ahora en el marco de una red de signos culturales y se considera, por consiguiente, que el proceso de traducción es una actividad transcultural que implica, al menos, dos culturas, dos lenguas, un universo abierto a múltiples interpretaciones y la particular intervención de un traductor. Se entiende así que la traducción, más que una actividad que se reduzca a descifrar o transcribir, es un amplio fenómeno de producción de sentido que abarca procesos de des-, re- y transcodificación, determinados por las capacidades y los conocimientos del traductor, la cultura en la que éste se inserta, la finalidad de la traducción y la especificidad de la situación comunicativa. La particular confluencia de estos factores conducirá inevitablemente a diferentes versiones de un mismo texto, a la politraducibilidad, un fenómeno que se evidencia fundamentado en la polinterpretabilidad textual.

Al incorporarse la variable sociocultural y la individualidad del intérprete como factores determinantes en el proceso traslativo, las viejas normas evaluativas basadas en dicotomías y en oposiciones binarias como bueno/malo, literal/libre, producción/reproducción, etc. deben cuestionarse. Ese modelo dicotómico, al otorgar exclusivamente al texto fuente la condición de original o creativo, coloca a la traducción en un plano secundario, lo que se manifiesta en la antítesis que se establece entre escritor versus traductor. Esta distinción entre escribir/traducir, diferencia al escritor, caracterizado por la originalidad, frente al traductor, que suele ser considerado derivativo o 'copista'. Mientras que a uno se le aplica la cualidad de autenticidad 
primigenia, al otro sólo se le exige la de fidelidad. De esta manera, en el mejor de los casos, la traducción suele considerarse sólo como una sombra o eco del original, incluso como una desnaturalización que falsea el sentido original (Ayala 1971: 364). De ahí que casi siempre al texto traducido se le haya atribuido una condición inferior, por otorgarse al original todo lo que es natural, auténtico y legítimo, y a la traducción únicamente lo artificial o falso (Álvarez Calleja 1995: 704). A este respecto, en un interesante estudio sobre la traducción, Barbara Folkart (1989) contempla el fenómeno traslativo, en cambio, como un acto creativo, como un proceso de recreación que deja su impronta y añade cualidades propias al texto fuente ${ }^{1}$. Para esta autora, traducir no es simplemente reproducir sino escribir; es decir, la traducción es una escritura productiva basada en el texto original, por lo que escribir y traducir son dos aspectos de una misma práctica creativa.

Por las consideraciones expuestas, estimamos justificado plantear la transformación de la conceptuación de la traducción desde una actividad reproductiva a otra productiva, desde una actividad secundaria a otra original, cuestionando la diferenciación tradicional entre autor y traductor, o sea, evitando contemplar el proceso traslativo desde la oposición binaria producción versus reproducción. Ello obliga a examinar de nuevo las jerarquías de escribir/producir y traducir/reproducir que inveteradamente han subordinado la actividad traslativa a la originalidad creadora, privilegiando la creación sobre la reproducción ${ }^{2}$. En ese caso, en lugar de valorarse la labor traslativa desde un criterio lingüístico basado en la absolutidad y condición isomorfa de las lenguas, en la supuesta validez de la equivalencia unívoca, deberá exigirse del texto traducido un funcionamiento en su propia cultura semejante al que cumplía el texto fuente en la suya, o sea, deberá prestarse especial atención a la función relativa de ambos textos -original y traducido- en cada uno de sus contextos, al particular funcionamiento de los valores culturales, así como a la actividad constructiva de sentido que el traductor realiza desde su peculiar perspectiva. Pues, en definitiva, más que lenguas, se traducen culturas. A partir de esta concepción de la actividad traslativa, se indagará en adelante acerca de las dificultades que plantea la traducción al castellano de la narrativa de Günter Grass.

\section{LOS TRADUCTORES DE GÜNTER GRASS AL CASTELLANO}

La obra de Günter Grass ha sido traducida en casi su totalidad al castellano. Sus ensayos hasta 1997 han aparecido recientemente -el volumen I en 2004 y el volumen II en 2005- en Galaxia Gutenberg/ Círculo de Lectores en una espléndida traducción realizada por Carlos Fortea y Joan Parra. La obra narrativa ha sido traducida por Carlos Gerhard (El tambor de hojalata, El gato y el ratón, Años de perro, Anestesia local), Genoveva Dieterich

\footnotetext{
${ }^{1}$ Véase a este respecto también Qianyuan (1995).

${ }^{2}$ Es conveniente recordar, a este respecto, que el propio Octavio Paz afirmaba que la traducción poética es una operación análoga a la creación poética, sólo que se desarrolla en sentido inverso. Y que Borges concebía que las traducciones más 'literarias' son el resultado de profundas lecturas y por ello admiraba la 'infidelidad' creadora de determinados traductores de Las mil y una noches -los franceses A. Galland y J. C. Mardrus y el inglés R. F. Burton- frente a la fidelidad rayana en la mediocridad de otros -el alemán E. Littmann-, pues en su opinión la infidelidad creadora procedía de un amplio conocimiento de la cultura literaria.
} 
(Encuentro en Telgte, Partos mentales o Los alemanes se extinguen), Anton Dieterich (Sacar la lengua) y Miguel Sáenz (Del diario de un caracol, El rodaballo, La Ratesa, Malos presagios, Es cuento largo, Mi siglo, A paso de cangrejo) ${ }^{3}$. También existen traducciones de su obra dramática y poética, realizadas por Juan José de Solar, Heleno Saña Alcón y Miguel Sáenz.

Tras la muerte de Carlos Gerhard, Miguel Sáenz está considerado como el traductor "autorizado" de Günter Grass al castellano. Además de a Grass, Miguel Sáenz ha traducido a Peter Handke, Franz Kafka, Thomas Bernhard, Arthur Schnitzler, Joseph Roth, Alfred Döblin, Salman Rushdie, Michael Ende y un largo etcétera. Por la traducción de El rodaballo, obtuvo el Premio Nacional de Traducción y el Premio Fray Luis de León, y por su versión de Es cuento largo recibió el Premio Aristeion. También ha sido galardonado con el Premio Nacional de Traducción de Austria y el Premio Goethe. La Universidad de Salamanca le invistió doctor honoris causa en Traducción e Interpretación. Miguel Sáenz es, sin duda, uno de los traductores al castellano actuales más prestigiosos. Pese a que está convencido que la traducción es un trabajo muy mal pagado y que por dinero no se puede traducir, a Miguel Sáenz le gusta traducir porque, en su opinión, "es la forma más atenta e intensa de leer, además da el placer de escribir sin el dolor del que tiene que crear algo completamente nuevo". Piensa que en el proceso de traducción "el texto es la partitura" y "traducir es como interpretar música". Cree, sin embargo, que no se debe "españolizar" demasiado al autor extranjero, por lo que suele respetar al máximo el texto original. Entiende que "esa otra mentalidad debe quedar reflejada en su lenguaje. Se puede importar un estilo que quizás no se le hubiera ocurrido nunca a un español y que a su vez repercute en el idioma castellano" 4 .

Miguel Sáenz mantiene una buena relación con Günter Grass, lo que no sorprende si se tiene en cuenta que Grass es uno de los pocos escritores alemanes que muestra un interés especial por las traducciones que se hacen de sus obras. Grass sabe valorar el trabajo del traductor, ya que es consciente de que su obra será conocida en otros países exclusivamente a través de las traducciones. Por ello suele reunirse con sus traductores en unos lugares que considera emblemáticos para sus novelas. Son unos encuentros que organiza su editorial cuando aparece una nueva obra. La necesidad de celebrar esos encuentros ya se evidenció en 1961. Aquel año Grass recibió una carta de Kurt Wolff, su editor en Estados Unidos, en la que le preguntaba, en nombre de Ralph Mannheim, el traductor de Die Blechtrommel, por el significado de la expresión "Angströhren". Sin embargo, la primera vez que se celebró un encuentro fue en la primavera de 1978, al objeto de preparar la traducción de Der Butt. El desencadenante de la reunión fue la pésima traducción que se había realizado de Die Blechtrommel al sueco. Los comentarios que hizo un germanista sobre los errores de esa traducción eran tan extensos como la obra misma. Ello impulsó a Günter Grass a incluir en las condiciones de publicación de Der Butt la aceptación por parte de su editor de entonces, Eduard Reifferscheid, de la organización y financiación de un encuentro con los traductores. Hasta ese momento ningún otro autor ni editorial alguna habían tomado

${ }^{3}$ Las novelas Es cuento largo y A paso de cangrejo las tradujo Miguel Sáenz con la colaboración de Grita Löbsack.

${ }^{4}$ El Pais, 23.04.1997. 
semejante decisión. Durante tres días consecutivos Grass se reunió con más de 20 traductores para discutir sobre dificultades lingüísticas y de comprensión del texto. El último encuentro con sus traductores lo ha celebrado Grass recientemente, en junio de 2005, en Gdansk, anteriormente Danzig, con motivo de la preparación de una nueva traducción de Die Blechtrommel, que se espera para 2007. Con una quincena de traductores de todo el mundo Grass leyó la obra con detenimiento, escuchó sus preguntas y comentó las propuestas para una nueva versión.

\section{LA TRADUCCIÓN DE LA OBRA NARRATIVA DE GÜNTER GRASS}

Günter Grass, un escritor crítico y comprometido con su tiempo, representante de la conciencia crítica y democrática de la cultura alemana, ha producido una extensa obra narrativa que evidencia un denominador común: las continuas referencias a la realidad política, social y cultural de Alemania, tanto del pasado como del presente. La Historia con mayúsculas, sobre todo la alemana, es el telón de fondo de las historias individuales de sus novelas. Así, a modo de ejemplo, en Die Blechtrommel muestra en detalle, a través de una crítica mordaz y una ironía despiadada, la historia más reciente de Alemania, sin ningún tipo de tabúes morales, religiosos o sexuales. En Der Butt reflexiona sobre casi cuatro mil años de historia de la humanidad, desde los tiempos prehistóricos hasta el alzamiento de los obreros de Gdansk, en los años setenta del siglo XX. A través del arte culinario y a partir del motivo alegórico del rodaballo, presenta unos acontecimientos que se desarrollan en once épocas diferentes. En la obra Das Treffen in Telgte ofrece, desde el trasfondo de la Guerra de los Treinta Años, un amplio pero preciso panorama de la literatura alemana del Barroco y del sentir de toda una época. Cuando se encuentran, los escritores del Barroco discuten sobre el uso correcto de la lengua alemana y reflexionan sobre la función del escritor y la literatura en la reconstrucción de un país devastado y dividido por una guerra atroz. La temática de Unkenrufe, al igual que la de su siguiente novela Ein weites Feld, gira en torno a la unificación de Alemania y sus consecuencias. En su última novela, Im Krebsgang, Grass narra el dolor que los propios alemanes sufrieron durante la Segunda Guerra Mundial.

En estas novelas, Grass somete el lenguaje a una constante invención léxica y sintáctica y adapta el estilo a la época concreta que describe, recurriendo incluso al dialecto de la Prusia oriental o al berlinés. Resulta así un lenguaje literario extraordinariamente rico y variado, plagado de neologismos. Desde un principio Grass fue consciente de que en plena posguerra sólo se podía escribir depurando la lengua alemana, limpiándola de la corrupción a la que fue sometida bajo el dominio del nacionalsocialismo, considerando aquel periodo como una cesura o ruptura irreparable de la historia de la civilización. Sólo así se podía esquivar el famoso veredicto de Theodor Adorno de que "escribir después de Auschwitz es una barbaridad". Sus preceptos eran la duda y el escepticismo. De este modo logró descubrir la riqueza de la lengua alemana, "ihre verführbare Weichheit, ihren vergrübelten Hang zum Tiefsinn, ihre durchaus biegsame Härte, ja, ihren mundartlichen Schmelz, ihre Einfalt und Vieldeutigkeit, ihre Verschrobenheiten und ihre in Konjunktiven aufblühende Schönheit" (Grass 1999: 36), como recuerda en Fortsetzung folgt... el discurso que pronunció el 7 de diciembre de 1999, ante la Academia Sueca, con motivo de la entrega del 
Premio Nobel de Literatura. Son precisamente ese convencimiento y esa compenetración con la lengua alemana, los que confieren una compacta intensidad semántica a la narrativa de Günter Grass, muchas veces de difícil traducción.

\subsection{Dificultades de la traducción de Ein weites Feld}

En 1995 Günter Grass publica Ein weites Feld, una extensa novela que describe los esfuerzos que Alemania ha realizado en los últimos siglos por alcanzar la unidad. La novela, que en su momento fue un best-seller y cuya aparición se llegó a celebrar como un acontecimiento nacional, ofrece una visión de la historia de Alemania desde la primera unificación en 1871 hasta la segunda en 1990, remontándose incluso a la Revolución de 1848, en cuyo transcurso se efectuó el primer intento por alcanzar la unidad, que acabó en fracaso. En el corto espacio de tiempo de casi dos años, que dura la acción narrativa, se muestra un amplio panorama de la historia de Alemania de los últimos 150 años, en el que tienen cabida el Vormärz, la Revolución de 1848, la fundación del Segundo Imperio, la Era Guillermina, la Primera Guerra Mundial, el Tercer Reich, la Segunda Guerra Mundial, el periodo de la RDA, la caída del muro y, por último, la reciente unificación. Particularmente, se establece un paralelismo entre la unificación de 1990 y la de 1871. El siglo XX se explica desde el trasfondo histórico de lo acontecido en el siglo XIX y, también, desde la propia historia de la literatura. Múltiples son las referencias a los poetas del Vormärz, a Uwe Johnson, Wolf Biermann, Christa Wolf o a la obra de Fontane, pero también a otros muchos autores, algunos poco conocidos, como, por ejemplo, Paul Heyse, un novelista de éxito del siglo XIX, o Friedrich Spielhagen, un teórico del Realismo. A través de una aguda intensidad intertextual se genera una amalgama sutil de realidad y ficción, en la que, de manera constante e intensa, lo histórico se mezcla con lo literario. Precisamente, a este propósito sirve el tratamiento que se da en Ein weites Feld a la figura central de Fontane. La novela aparece repleta de citas y referencias al famoso escritor del Realismo alemán, a través de las cuales se evoca la historia de Alemania, se presenta la sociedad de la época y se alude a un sinnúmero de acontecimientos políticos y culturales.

Para el traductor, supone un auténtico reto explicitar, completar y verter a la cultura de llegada esta ingente cantidad de información, sobre todo la que atañe al amplio trasfondo histórico de la novela, a su contexto geográfico, político, social y cultural. Las múltiples referencias literarias, en particular las concernientes a la vida y obra de Fontane, acrecientan esas dificultades, que requieren del traductor una rigurosa labor de documentación y de interpretación del texto original. Esto ocurre ya con el título de la novela. En alemán la expresión "ein weites Feld sein" significa "ein schwer überschaubarer Bereich sein", o bien, "ein Thema sein, über das sich viel sagen ließe" (Duden). Pese a ello, la primera vez que se tradujo al castellano el título de Ein weites Feld, una expresión que Grass tomó de Effi Briest, la obra más famosa de Fontane, se hizo de manera literal. Se vertió como "Un amplio campo" (El País, 28.4.1995, José Comas y El País, 28.8.1995, Reuter), "Un campo lejano" (El País, 23.8.1995, Lino Ventosinos) o "Un vasto campo" (El País, 29.8.1995 y 31.8.1995, Lino Ventosinos). Otras traducciones se acercaron más al sentido original de la expresión: "Una larga historia" (El País, 22.8.1995, AFP). Al catalán Joan Fontcuberta lo tradujo como "Una llarga història" y en castellano Miguel Sáenz eligió la frase "Es cuento 
largo", que aparece en la escena sexta de Luces de bohemia de Ramón María del ValleInclán.

Para que el lector pueda comprender adecuadamente el desarrollo de la acción narrativa de Ein weites Feld y pueda alcanzarse la llamada "equivalencia comunicativa", muchas de las expresiones relativas al contexto geográfico, político, social y cultural en el que se inserta lo narrado, requieren de una explicación adicional en la cultura de llegada, que puede incorporarse como nota a pie de página o mediante aposiciones, como así hace, en numerosas ocasiones, Miguel Sáenz en su traducción al castellano de la novela. Larga es la lista de esas expresiones. A continuación, a modo de ejemplo, presentamos algunas de ellas, cuya aclaración se indica entre paréntesis tras la traducción:

\section{Fechas y acontecimientos históricos}

der 17. Juni

August einundsechzig

der 18. März

Montagsdemonstrationen

der 4. November

Vierpluszweigespräche

das mißglückte Attentat

der Barbie-Proze $\beta$

el 17 de junio (el 17 de junio de 1953 se produjo un levantamiento obrero en Berlín Oriental)

Agosto del sesenta y uno (el 13 de agosto de 1961 comenzó la construcción del muro de Berlín)

el 18 de marzo (el 18 de marzo comenzó la Revolución de 1848 en Berlín)

Las manifestaciones de los lunes (manifestaciones que comenzaron el 11 de septiembre de 1989 en la iglesia de San Nicolás de Leipzig, y siguieron realizándose todos los lunes hasta que llegó la unificación alemana)

aquel 4 de noviembre (fecha de la mayor manifestación celebrada en 1989 en Berlín oriental, en la que participó cerca de un millón de personas que reclamaban elecciones libres)

Conversaciones del Cuatro por Dos (negociaciones de la primavera de 1990 entre las cuatro potencias aliadas -EE.UU., Gran Bretaña, Francia y la Unión Soviética- y los dos Estados alemanes en torno a las condiciones de la unificación)

el fracasado atentado (el atentado fallido contra Hitler del 20 de julio de 1944)

el proceso Barbie (proceso incoado en 1987 contra Klaus Barbie, jefe de la Gestapo en Lyon) 
Wannseekonferenz

\section{Lugares y monumentos}

Meine Frau Mama, zum Beispiel, die waschecht vom Wedding stammte

Alex

Amazona

Buchenwald

Normannenstrasse

Nombres propios

Honni oder Gorbi

Herwegh
Conferencia del Wannsee (conferencia celebrada en 1942 en Berlín, en la que los dirigentes del Tercer Reich decidieron la llamada "solución final" de la cuestión judía)

Mi madre, por ejemplo, que era de Wedding por los cuatro costados (Wedding es un barrio obrero de Berlín)

Alexanderplatz (famosa plaza en el centro de Berlín)

Amazona (estatua ecuestre femenina en el Parque Zoológico de Berlín)

Buchenwald (campo de concentración nazi en las cercanías de la ciudad de Weimar)

La Normannenstrasse (en esta calle tenía su sede la central de la Stasi)

Honni o Gorbi (Erich Honecker, secretario general del Comité Central del SED, el partido comunista de la RDA, y posteriormente presidente de la RDA, y Gorbachov, presidente de la Unión Soviética)

Herwegh (Georg Herwegh fue un escritor revolucionario del siglo XIX)

Periódicos, revistas e instituciones culturales

Adlerzeitung

Adlerzeitung (periódico conservador, que fue entre 1851 y 1853 órgano oficial del Gobierno Manteuffel, un político prusiano de ideas conservadoras)

Pan

Pan (Publicación trimestral especializada en arte que fue fundada, entre otros, por Fontane. Apareció en Berlín entre 1895 y 1899) 
Tunnelbrüder

Freie Bühne

Kulturbund

Expresiones de la RDA

Jugendweihe

Interflug

Wartburg in Eisenach

Trabi

Rotkäpchen

Friedenswall

Schutzwall

Alusiones

die regierende Masse

wegen dem Schreihals, der hier nicht singen durfte
Compañeros del Tunnel (alusión a la asociación artística Tunnel über der Spree)

Freie Bühne (asociación teatral fundada en 1889 que organizaba a puerta cerrada, sólo para socios, representaciones de obras de la joven generación de escritores, a fin de evitar la censura)

la Kulturbund (Organización oficial en la RDA dedicada al servicio de la cultura)

Fiesta de la juventud (el equivalente laico, en la RDA, de la comunión o confirmación religiosas. Era una ceremonia de iniciación de los adolescentes de 14 años a la vida adulta)

La Interflug (compañía aérea estatal de la RDA)

La Wartburg de Eisenach (Compañía estatal de automóviles)

Trabi (nombre popular de los Trabant, coches fabricados en la RDA entre 1951 y 1991)

Caperucita Roja (marca de champán muy popular en la RDA)

Muro de la paz (nombre que recibía el muro de Berlín en la RDA)

Muralla de protección (nombre que recibía el muro de Berlín en la RDA)

la "Masa gobernante" (Helmut Kohl)

por culpa del "Gritón", al que no dejaban cantar aquí (Wolf Biermann, escritor y cantautor) 
"der Mann mit den Ohren"

der Hencker in Plötzensse el "Hombre de las Orejas" (Hans-Dietrich Genscher, entonces ministro de Asuntos Exteriores)

el verdugo en Plötzensse (establecimiento penitenciario de Berlín-Charlotemburgo, en donde, entre 1933 y 1945, fueron asesinados más de 2.000 adversarios políticos del nacionalsocialismo)

jenem Agustinermönch nicht unähnlich war, der einst vor versammeltem Reichstag sein "Ich kann nicht anders" zur Redensart gemacht hatte

no dejaba de parecerse a aquel monje agustino que en otro tiempo, ante la Dieta del Imperio reunida, convirtió en giro coloquial su "No puedo hacer otra cosa" (Lutero)

»Pasewalk - nie! « Hier hat doch dieser österreichische Gefreite im Lazarett gelegen und beschlossen, Politiker zu werden

Pasewalk... ijamás! Aquí es donde aquel cabo austríaco estuvo en un hospital militar y decidió ser político (Adolf Hitler)

Eine Heilige wurde zur Staatshure erklärt Una santa fue declarada puta oficial (Christa Wolf, la novelista más importante de la RDA, que tras la publicación de su obra Was bleibt fue objeto de feroces críticas)

angebebelt

contagiado de las ideas de Bebel (August Bebel, 1840-1913, cofundador y líder de la socialdemocracia alemana)

die »Sputnik«-Affäre

El asunto de la revista Sputnik (el 18 de noviembre de 1988, la revista soviética Sputnik fue prohibida en la RDA, por condenar los crímenes de Stalin)

die drei großen $B$ las tres bes mayúsculas (Bach, Beethoven y Brahms)

\section{Siglas}

FDJ

FDJ (Freie Deutsche Jugend -Juventud Alemana Libre-, organización de las juventudes comunistas en la RDA)

Stasi

Stasi (Staatssicherheit, servicio secreto de la RDA)

Die Regale in allen HO- und Konsumläden Las estanterías de todos los comercios de la $\mathrm{HO}$ y de las cooperativas de consumo $(\mathrm{HO}=$ 
Brennerei VEB

KaDeWe

Otras expresiones

Begrïßungsgeld

Treuhand

Paternoster

[er] verlangte nach Fachinger
Handelsorganisation, Organización de Comercio, única organización estatal de comercio al por menor en la RDA)

La destilería VEB (Volkseigener Betrieb, es decir, empresa de propiedad popular)

$\mathrm{KaDeWe}$ (KDW, grandes almacenes en Berlín)
Subvención de bienvenida (subvención que por valor de 100 marcos se daba, después de la caída del muro, a todos los ciudadanos de la RDA que presentaran su documento de identidad)

Treuhand (agencia estatal encargada, entre 1990 y 1995, de la privatización de las antiguas propiedades públicas de la RDA)

paternóster / montacargas de personas

pidió Fachinger (conocida marca de agua mineral)

\subsection{La traducción de Mein Jahrhundert}

En 1999 Grass publica Mein Jahrhundert, una obra compuesta de cien historias cortas, una por año, en las que hace un balance del siglo XX cada vez desde una perspectiva distinta. Los temas tratados son amplios y variados: las Guerras Mundiales, campeonatos de fútbol, encuentros ficticios entre escritores, la política, la unificación de Alemania, la Treuhand, huelgas y luchas sociales, y también momentos de la vida del autor. Siguiendo un orden cronológico, las historias están narradas desde el punto de vista y las vivencias de los que no tienen poder, de los que han vivido la Historia como destino y han tenido que reaccionar ante ella, algunas veces como víctimas, otras como verdugos o cómplices. Son narradores múltiples, alguno tan inusual como el propio autor en el útero materno, que ofrecen su particular visión de la historia de Alemania y de buena parte de la historia del mundo del siglo XX. En estas historias, Grass recurre a las diversas variantes que ofrece el género narrativo: el relato autobiográfico, el informe, la crónica, el monólogo interior o la descripción vivencial.

Pese al amplio trasfondo histórico, geográfico, político, social y cultural en el que se insertan las historias, la traducción que existe en castellano de Mein Jahrhundert carece de 
notas y de precisas explicaciones adicionales, que sólo se ofrecen en contadas ocasiones a modo de aposiciones. Se trata de una traducción bastante literal, en la que, sorprendentemente, el traductor que la suscribe, que ya ha demostrado con creces su valía, competencia y rigor profesional, incurre en errores que pueden calificarse, simple y llanamente, "de bulto". Comentamos a continuación algunas de esas inexactitudes de incomprensible factura. Los números de página indicados entre paréntesis se refieren, respectivamente, a la edición de la obra en alemán y a la de su traducción al castellano. Ambas ediciones aparecen señaladas en las referencias bibliográficas.

Völkerschlacht (p. 50) se traduce como "Batalla de los Pueblos" (p. 69), cuando el nombre habitual en castellano es el de "Batalla de las Naciones".

Zürichsee (p. 59) se vierte como "lago de Zürich" (p. 81), cuando en realidad el nombre de la ciudad suiza debe escribirse en castellano "Zúrich", con tilde (Seco 2001: 465; Real Academia Española 2005: 687).

Sandmännchen (p. 91) se traduce como "hombrecitos de arena" (p. 123). Sin embargo, debería traducirse como "hombrecillos de la arena", puesto que no están hechos de arena, sino que arrojan arena a los ojos de los niños para que se les cierren los párpados a la hora de dormir, por lo que también podría traducirse como "duendecillos del sueño".

Herbst dreiundfünfzig (p. 104) se traduce como "otoño del treinta y cinco" (p. 139). La expresión, no obstante, se refiere al otoño del año $1953^{5}$. Debido a este error, el lector de la traducción al castellano no podrá comprender correctamente una de las historias centrales de Mi siglo. Es un relato, correspondiente a 1928, en el que se resume la historia política de Alemania durante gran parte del siglo XX. Una madre proveniente de una familia socialdemócrata recuerda, años después de la Segunda Guerra Mundial por eso es importante la fecha de 1953-, lo que fue de sus tres hijos: el mayor se hizo policía en la República de Weimar, el segundo se integró en el Partido Comunista y el más joven se alistó en las SA.

... dankte ich dem Gastgeber, einem Ehemaligen, der sich ... eines dieser reetgedeckten Friesenhäuser auf Sylt leisten konnte (p. 140) se vierte como "di las gracias al anfitrión, un veterano que ... podía permitirse una de esas casas frisias cubiertas de caña" (p. 186), sin que se traduzca "auf Sylt". Se trata de un relato, correspondiente al año 1939, en el que se presenta la Segunda Guerra Mundial desde la perspectiva de un antiguo corresponsal de guerra alemán, que organiza un encuentro de viejos colegas en la isla de Sylt. Durante los días que dura la reunión, hablan de la campaña de Polonia y de la Blitzkrieg. El lector de la versión castellana, sin embargo, no sabrá que esa reu-

\footnotetext{
${ }^{5}$ Un error semejante aparece en la traducción al castellano de la novela de Günter Grass Im Krebsgang. La expresión "Nach Moskauer Zeit war es dreiundzwanzig Uhr" (p. 130) aparece traducida como "Según la hora de Moscú eran las tres y veinte" (p. 146). Obviamente, se trata de las veintitrés horas. La obra trata del hundimiento en las gélidas aguas del Báltico, el 30 de enero de 1945, por tres torpedos de un submarino ruso, de un barco alemán, el Wilhelm Gustloff, con más de 10.000 personas a bordo que huían del avance soviético. La hora a la que se refiere la frase traducida erróneamente es de crucial importancia, por cuanto señala el momento del lanzamiento del primer torpedo, que da inicio a una sucesión de hechos y acciones, cuya cronología el lector de la traducción al castellano no podrá establecer de manera coherente.
} 
nión se celebra, precisamente, en la isla de Sylt, ya que en la traducción se ha suprimido cualquier referencia al lugar.

SED-Mitglied (p. 176) se traduce como "miembro del Partido Unitario Socialista de Alemania" (p. 234). Las siglas SED (Sozialistische Einheitspartei Deutschlands), el antiguo partido comunista de la RDA, deben traducirse, sin embargo, como "Partido Socialista Unificado de Alemania”.

Die Herren Richter alle, die gut deutsch reden konnten (p. 224) se traduce como "Los señores magistrados todos, que podían hablar bien alemán" (p. 294), cuando en realidad, en castellano, habría que decir "que sabían hablar bien alemán".

Junge Union (p. 234) se vierte como "Unión Juvenil" (p. 307), una denominación incomprensible en castellano. Se debería traducir como "juventudes de la CDU" o "juventudes democristianas".

gegen den Paragraphen 218 (pp. 235 y 265) se traduce como "contra el párrafo 218 " (pp. 308 y 345), cuando en castellano se debería traducir como "contra el Artículo 218". No obstante, considerando que ese artículo regula en Alemania la interrupción voluntaria del embarazo, una circunstancia posiblemente desconocida por el lector al que va dirigida la versión castellana, la expresión se podría traducir más correctamente como "contra la legislación del aborto".

En definitiva, son muchas y diversas las dificultades que entraña la traducción al castellano de la obra narrativa de uno de los escritores más reconocidos de la literatura alemana.

\section{REFERENCIAS BIBLIOGRÁFICAS}

ALBALADEJO, T., "Aspectos pragmáticos y semánticos de la traducción del texto literario", Koiné, 2, 1-2, 1992, 179-200.

ÁLVAREZ CALLEJA, Ma A., "Traducción literaria: creación vs. re-creación”, en: R. MartínGaitero (ed.), V Encuentros Complutenses en torno a la Traducción, Madrid, Editorial Complutense, 1995, 703-709.

AYALA, F., Los ensayos. Teoría y Crítica Literaria, Madrid, Aguilar, 1971.

REAL ACADEMIA ESPAÑOLA/ ASOCIACIÓN DE ACADEMIAS DE LA LENGUA ESPAÑOLA, Diccionario panhispánico de dudas, Madrid, Santillana, 2005.

SECO, M., Diccionario de dudas y dificultades de la lengua española, Barcelona, Círculo de Lectores, $2001^{10}$.

DUDEN, Deutsches Universal Wörterbuch, Mannheim/ Wien/ Zürich, Dudenverlag, 2001.

ECO, U., La búsqueda de la lengua perfecta, Barcelona, Grijalbo-Mondadori, 1994.

ELENA GARCÍA, P., Aspectos teóricos y prácticos de la traducción, Salamanca, Universidad de Salamanca, 1990.

FOLKART, B., "Translation and the Arrow of Time", TTR 2, 1, 1989, 19-50. 
GARCÍA YEBRA, V., "La traducción en el nacimiento y desarrollo de las literaturas", 1616, Anuario de la Sociedad Española de Literatura General y Comparada, 4, 1981, 7-24.

GRASS, G., Ein weites Feld, ed. de Daniela Hermes, Göttingen, Steidl, $1997\left(1995^{1}\right)$. [Trad. cast.: Es cuento largo. Trad. de Miguel Sáenz (con la colaboración de Grita Loebsack), Madrid, Alfaguara, 1997.]

GRASS, G., Mein Jahrhundert, ed. de Volker Neuhaus, Göttingen, Steidl, 1999. [Trad. cast.: Mi siglo. Trad. de Miguel Sáenz. Madrid, Punto de lectura, S.L., 2001.]

GRASS, G., Fortsetzung folgt ... / Literatur und Geschichte, Göttingen, Steidl, 1999.

GRASS, G., Im Krebsgang. Eine Novelle, ed. de Daniela Hermes, Göttingen, Steidl, 2002. [Trad. cast.: A paso de cangrejo. Trad. de Miguel Sáenz (con la colaboración de Grita Loebsack), Madrid, Alfaguara, 2003.]

MORILLAS, E./ ARIAS, J. P. (eds.), El papel del traductor, Salamanca, Colegio de España, 1997.

QIANYUAN, G., "Das Wesen des Übersetzens ist kreativ", Babel,41, 3, 1995, 129-139.

STOLZE, R., Übersetzungstheorien. Eine Einführung, Tübingen, Narr, $1997^{2}$. 